Article

\title{
Modular Lead-Bismuth Fast Reactors in Nuclear Power
}

\section{Georgy Toshinsky ${ }^{1,2, *}$ and Vladimir Petrochenko ${ }^{2}$}

1 State Scientific Center Institute for Physics and Power Engineering (SSC IPPE), 1, Bondarenko Sq., Obninsk, Kaluga Rg. 249033, Russia

2 JSC “AKME Engineering”, 13, Pyatnitskaya St., Bld. 1, Moscow 115035, Russia; E-Mail: V.Petrochenko@svbr.org

* Author to whom correspondence should be addressed; E-Mail: toshinsky@ippe.ru; Tel.: +7-484-399-85-35; Fax: +7-484-396-82-25.

Received: 27 June 2012; in revised form: 15 August 2012 / Accepted: 24 August 2012 / Published: 18 September 2012

\begin{abstract}
On the basis of the unique experience of operating reactors with heavy liquid metal coolant-eutectic lead-bismuth alloy in nuclear submarines, the concept of modular small fast reactors SVBR-100 for civilian nuclear power has been developed and validated. The features of this innovative technology are as follows: a monoblock (integral) design of the reactor with fast neutron spectrum, which can operate using different types of fuel in various fuel cycles including MOX fuel in a self-providing mode. The reactor is distinct in that it has a high level of self-protection and passive safety, it is factory manufactured and the assembled reactor can be transported by railway. Multipurpose application of the reactor is presumed, primarily, it can be used for regional power to produce electricity, heat and for water desalination. The Project is being realized within the framework of state-private partnership with joint venture OJSC "AKME-Engineering" established on a parity basis by the State Atomic Energy Corporation "Rosatom" and the Limited Liability Company "EuroSibEnergo".
\end{abstract}

Keywords: lead bismuth; fast reactor; reactor safety; SVBR-100; potential energy; nuclear fuel cycle; uranium oxide 


\section{Abbreviations}

$\begin{array}{llll}\text { BR } & \text { breeding ratio } & \text { NPP } & \text { nuclear power plant } \\ \text { CBR } & \text { core breeding ratio } & \text { NPT } & \text { nuclear power technology } \\ \text { CPS } & \text { control and protection system } & \text { NS } & \text { nuclear submarine } \\ \text { FR } & \text { fast reactor } & \text { NSSS } & \text { nuclear steam supplying system } \\ \text { FOAK } & \text { first of a kind } & \text { PHRS } & \text { passive heat removal system } \\ \text { FSA } & \text { fuel subassembly } & \text { PWR } & \text { pressurized water reactor } \\ \text { HLMC } & \text { heavy liquid-metal coolant } & \text { R\&D } & \text { research and development works } \\ \text { INPRO } & \text { IAEA International Project } & \text { RAW } & \text { radioactive waste } \\ \text { LBC } & \text { lead-bismuth coolant } & \text { RF } & \text { reactor facility } \\ \text { LF } & \text { loading factor } & \text { RMB } & \text { reactor monoblock } \\ \text { LMC } & \text { liquid-metal coolant } & \text { SG } & \text { steam generator } \\ \text { LOCA } & \text { loss of coolant accident } & \text { SNF } & \text { spent nuclear fuel } \\ \text { LWR } & \text { light water reactor } & \text { SSC } & \text { State Scientific Center of Russian } \\ & & \text { RF-IPPE } & \text { Federation-Institute for Physics and } \\ & & & \text { Power Engineering } \\ \text { MA } & \text { minor actinides } & \text { SSC } & \text { State Scientific Center-Research } \\ & & \text { RIAR } & \text { Institute of Atomic Reactors } \\ \text { MCP } & \text { main circulation pump } & \text { SVBR } & \text { lead-bismuth cooled fast reactor } \\ \text { MOX- } & \left.\text { mixed oxide (mixed } \mathrm{PuO}_{2}+\mathrm{UO}_{2}\right) & \text { TPP } & \text { thermal power plant } \\ \text { fuel } & \text { fuel } & & \\ \text { NC } & \text { natural circulation } & \text { TR } & \text { thermal reactor } \\ \text { NFC } & \text { nuclear fuel cycle } & \text { WWER } & \text { water cooled water moderated } \\ & & & \text { power reactor } \\ \text { NP } & \text { nuclear power } & & \\ & & & \end{array}$

\section{Introduction}

Reliable power supply is a basis for sustainable development and the existence of mankind. Currently the basic power source that can solve the problem from the standpoint of possible constraints on fuel resources and elimination of harmful effects on the environment is nuclear power (NP) based on fast reactors (FR) operating in a closed nuclear fuel cycle (NFC). This was clear in the earliest stage of NP development when E. Fermi (the USA) and A.I. Leypunsky (the USSR) validated the possibility to realize extended plutonium breeding in FRs that enabled the NP fuel base to be increased by approximately one hundred times.

At the same time, despite the highlighted unchallengeable advantages over thermal reactors (TR), currently FRs are not widespread. Moreover, in many countries the leading experts consider that implementation of FRs for NP will be postponed until the second part of the current century or further because cheap resources of natural uranium have not yet been exhausted.

The point is that FRs developed for high rate buildup of plutonium (short doubling time), which is possible only if sodium coolant is used, turned out to be more expensive compared with TRs. 
At the same time, even in the event of high increase of the cost of natural uranium, for the electricity market the NPPs with thermal neutron reactors will be competitive with thermal power plants (TPP) for a long time.

This is conditioned by the fact that the cost of electricity produced by the NPP is not sensitive to the cost of natural uranium, contrary to the cost of electricity produced by the TPP, which is mainly determined by the cost of fossil fuel. Along with this, the available resources of natural uranium are growing progressively due to increasing the investment and rate of carrying out exploration works

The severe accidents which happened at NPP TMI and in Chernobyl caused a huge increase in safety requirements. It is expected that they will be even stricter after the accident occurring at NPP Fukushima 1. To meet these requirements, the NPPs have begun to be equipped with a large number of safety systems, which both diminish the probability of severe accidents and the extent of their consequences. As a result, the capital costs of NPP construction and expenditures for NPP operation have increased considerably which has lessened the NP competitiveness.

To diminish the specific capital expenditures and reduce the cost of electricity, a considerable increase of unit power capacity up to $1500 \mathrm{MWe}$ and more is required. However, an increase of reactor unit power will cause both an increase of the NPP total cost and the construction period which will result in deterioration of investment attractiveness of the project. Moreover, the market for power-units of high capacities is constrained by a small number of countries with developed power-systems for high capacities. The difficulties in selection of sites suitable for construction of high capacity power-units are also increasing. These points all refer to the evolutional projects for sodium reactors as well. The conflict between economic and safety requirements is characteristic to all traditional nuclear power technologies (NPT).

The highlighted problems as well as other problems, which should be solved when developing large-scale NP, have resulted in the necessity to develop innovative NPTs. Such works are being carried out within the framework of the international project INPRO, managed under the IAEA aegis. The proposed basic principles specify [1] that it must be assured that the catastrophic release of radioactivity is eliminated, with due account to all expenditures and credits. The cost of energy generated by the NPP on the basis of that NPT must be competitive with the cost of energy generated by alternative energy sources; otherwise, alternative technologies will force out nuclear technologies from the market. Moreover, the innovative NPT must be investment-attractive compared with other power technologies. With this, all expenditures for the life cycle including those for technology demonstration should be taken into account.

In different countries and regions of the world the economical requirements for NPT can differ much, but the requirements for safety, management of radioactive waste (RAW), nonproliferation of nuclear fissile materials (NFM) due to the global character of the consequences of their violation must be the same and provide social-political acceptance of the NPT. For that reason, all these points must be established by the world community managed under the IAEA aegis.

The highlighted problems above can be solved in the aggregate provided we use innovative NPT, in which there is no intrinsic conflict between the economic and the safety requirements peculiar to all traditional NPT and conditioned by the high value of potential (non-nuclear) energy stored in the coolant. 
The technology that is mostly available for practical implementation is that based on application of modular multi-purposed small power fast reactors $(100 \mathrm{MWe})$ with heavy liquid-metal coolant (HLMC) - eutectic lead-bismuth alloy, which possess developed properties of inherent self-protection and passive safety, i.e., SVBR-100 [2]. This technology has been mastered in Russia [3] for nuclear submarines' (NS) reactors.

\section{Expedience and Opportunity to Use Lead-Bismuth Eutectic Alloy as Fast Reactor Coolant}

In 1950 lead-bismuth coolant in fast reactors was first examined by A. I. Leypunsky [4] while assessing the opportunity to construct a breeder-reactor. However, the heat transfer properties of that coolant being low, compared to those of sodium, did not allow sufficiently high power density in the core together with having a short doubling time in breeding plutonium, even at a breeding ratio (BR) that much exceeded 1. For that reason, when fast breeder-reactors were further developed, sodium was selected as the coolant.

However, now and in the foreseeable future, the task of development and implementation in NP the large NPPs sector based on FRs of providing a short doubling time of plutonium and a high pace of NP development without consumption of natural uranium is becoming much less actual. Therefore, an opportunity to consider the use of lead-bismuth coolant (LBC) in FRs, with due account to the experience gained of its application for NS reactors, re-emerges.

Low pressure in the primary circuit reduces the risk of tightness failure and allows a reduction in the thickness of the reactor vessel walls. It also reduces the limitations imposed on a rate of temperature change associated with the strength of thermal-cycling.

A high boiling point of coolant $\left(\sim 1670{ }^{\circ} \mathrm{C}\right)$ heightens the reliability of heat removal from the core, and assures safety due to lack of a crisis due to heat transfer. Moreover, coupled with a safeguard casing of the reactor vessel, loss of coolant accidents (LOCA) have been eliminated.

LBC is chemically inert. It reacts only slightly with water and air. Progression of the processes caused by tightness loss in the primary circuit and the steam generator's (SG) inter-circuit leaks will occur without release of hydrogen and without any exothermic reactions. There are no materials within the core and reactor facility which release hydrogen as a result of thermal and radiation effects and chemical reactions with coolant. Therefore, the likelihood of chemical explosions and fires as internal events is virtually eliminated.

Lead and bismuth are weak absorbers of neutrons. However, they are good scatterers (not moderators). These facts beneficially affect the neutron-physical characteristics of the reactor. In addition, LBC density strongly depends on temperature which contributes to development of natural circulation.

Low heat-transfer properties of LBC (compared with those of sodium) do not make it possible to obtain a high power density of the core and a short doubling time of plutonium even noticeably in the case where BR exceeds 1. At the same time, due to the natural properties of HLMC, the reactor facility (RF) can be much simplified and its cost can be reduced.

When speaking about the wide use of LBC cooled RFs in nuclear power, it is necessary to consider the specific issues concerning use of bismuth in coolant. These issues are as follows: the radiation hazard of alpha-active polonium-210 radionuclide formed in the process of irradiating bismuth with 
neutrons, the high cost of bismuth, the small scale of bismuth production and insufficient exploration of bismuth resources.

In connection with the above mentioned questions the following should be highlighted:

1) Experience of operating the NS RFs has resulted in developed measures of providing radiation safety, excluding over-permissible irradiation of the personnel, who stayed in the NS compartments in events of accidental LBC leaks and performed repair and maintenance works. All the personnel were under periodical medical observations. On the basis of the numerous radiometric investigations of biological samples of the personnel (military and civilians), it was clearly established that there were no events of polonium intake over the permissible values. This fact validated a high efficiency of used individual and collective protection measures, the right option for the technology and correct organization of repair-maintenance works [5]. Having carried out the investigations and analyzed the gained experience, the American and Japanese experts also have come to the conclusion that the formation of polonium in LBC cannot hamper its future use in the NP.

The paper published in the USA [6] summarizes the data of the retrospective analysis on mortality among the personnel (about 4500 men) who dealt with works with Po-210 in 1944-1972 and whose internal intakes of Po-210 were examined. The authors made a conclusion that there was no connection between the doses of internal intake caused by $\sim 1 \mathrm{~Sv}$ (100 rem) of incorporated polonium and the death-rate caused by cancer. For the examined personnel almost all trends characterizing the death-rate caused by various cancer diseases were negative, i.e., the death-rate was even less than that for the control groups of people who had not dealt with polonium.

It should be highlighted that due to the monoblock (integral) design of the primary circuit equipment and safeguard casing over the monoblock vessel, leaks of coolant are virtually eliminated for the SVBR-100 RF. The probability of radioactive gas release is also reduced considerably as argon pressure in the gas system approximately equals atmospheric pressure.

2) The available reference information on explored bismuth resources has not included discussion about the wide use of LBC in large scale NP. However, just recently, the specialized Rosatom enterprises such as OAO "Atomredmetzoloto" and VNIPI of industrial technology made technical and economic investigations into opportunities to organize large scale bismuth production in Russia and estimated bismuth resources in the Commonwealth of Independent States. The results revealed that only on the basis of the explored bismuth mines in Chita region in Russia it is possible to provide profitable production of bismuth in quantities sufficient enough to put in operation at an annual rate of $1 \mathrm{GWe}$ for approximately $70 \mathrm{GWe}$ of NPPs with LBC cooled FRs [7]. Moreover, there are large bismuth resources in the North Caucasus. Also, it is possible to put in operation $\sim 300 \mathrm{GWe}$ on exploiting the bismuth mines in Kazakhstan. According to assessments made by Japanese experts, the available bismuth resources worldwide are $\sim 5$ million tons [8].

It should be highlighted that according to a geological-economic general law, the quantity of mineral raw ore increases proportionally to the square of the cost that consumers are willing to pay for the resources. For the current bismuth prices, its contribution to the capital cost for constructing the NPP based on considered FRs is $\sim 1 \%$. 
As development of LBC cooled FRs is based on experience of LBC application in the NS reactors, the gained experience is described briefly.

\section{Expedience and Brief Description of Experience of LBC Usage}

In the early 1950s, at about the same time the USA and the USSR launched their development programs on reactor facilities for NSs both countries developed two types of reactors: pressurized water reactors and liquid-metal cooled reactors.

In the USA sodium was selected as liquid-metal coolant because its thermal-physical characteristics were better compared to those of LBC. The ground-based test facility-prototype of the RF and experimental NS "Seawolf” were constructed.

However, operating experience revealed that the option for the coolant, which was a fire- and explosion-hazard in the event of contact with air and water, did not justify it. So the NS was decommissioned together with the compartment and replaced by a pressurized-water reactor facility. The research and development works (R\&D) on mastering lead-bismuth coolant were also carried out in the USA. However, the selected approach of finding the solution to the problem of corrosion resistance of structural materials, control and coolant quality maintenance (coolant technology) did not lead to positive results, and works were stopped.

From the very beginning in the USSR, lead-bismuth eutectic alloy was selected as liquid-metal coolant. It was clear that the problem of LBC technology was viable after a severe accident happened at Project 645 in 1968 (it should be highlighted that even in conditions of the severe accident, coolant pressure did not increase, primary circuit tightness was not lost, radioactive contamination of air in the reactor compartment did not occur [9]), in which part of the core melted in the reactor at the NS left side. This happened because of ingress of a large quantity of accumulated slag (lead oxides) at the core inlet. For fifteen years certain organizations carried out works on mastering the lead-bismuth coolant's technology under the scientific supervision of SSC RF-IPPE. As a result, the problem of lead-bismuth coolant technology was solved successfully. It was found that reliable operation of the RF required that the concentration of oxygen dissolved in LBC should be maintained within a certain range [10] which could be realized automatically. Long years of experience of operating the NSs' RFs has verified their reliable operation [9]. Along with the other problems, the problem of multiple LBC "freezing-unfreezing" was solved by maintaining operability of the equipment. However, this problem is much less important for RF SVBR-100.

As operating experience has revealed, the amount of liquid radioactive waste is very low due to lack of the necessity to perform decontamination in the primary circuit while performing repair works and refueling.

A significant shortcoming in the design of the RFs was a branched structure of the primary circuit. This disadvantage is excluded in the design of RF SVBR-100.

Altogether 15 reactors at two ground facility-prototypes (SSC RF-IPPE (Obninsk) and NITI (Sosnovy Bor)) and eight nuclear submarines with LBC cooled RFs were in operation. The first experimental NS of Project 645 had two reactors. Each of the other seven NSs of Project 705 (in terms of NATO - “Alpha") had one reactor (Figure 1). Due to its speed and maneuvering characteristics the NS was entered into the Guinness Book of Records. 
Figure 1. NSs of Project 705.

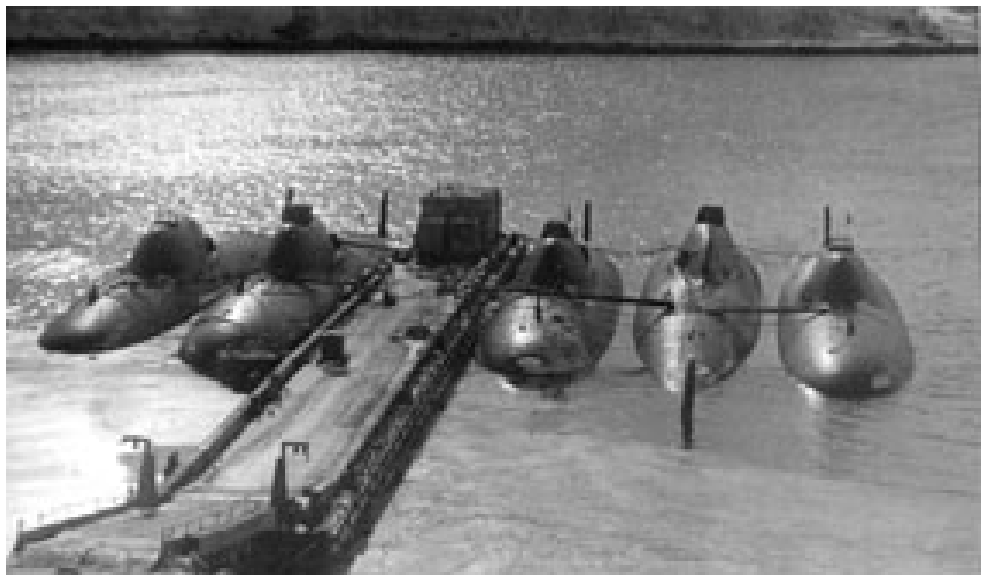

The total operating time of the considered type of reactor facilities in all modes was $\sim 80$ reactor-years. The innovative nuclear power technology that had no analogues in the world was demonstrated on the industrial scale. Currently with due account of gained experience the conditions for implementation of this technology into civilian NP are available.

\section{Approach to Selection of the RF Type by a Value of Stored Potential Energy}

During the historically short period of NP mastering, use of nuclear power was followed by a number of low probability accidents of various extents of severity, which caused strong escapes of radioactivity into the environment and/or considerable economic losses. The accidents occurred were as follows:

- Three Mile Island Unit 2 (TMI-2, USA) accident occurred in 1979. The accident in PWR type reactor at nuclear power plant (NPP) resulted in core meltdown due to loss of primary circuit coolant caused by technical failure (the safety valve remained open) and inadequate actions of personnel. Today, the TMI-2 reactor is permanently shutdown, radioactivity has been localized within the containment;

- The Chernobyl disaster occurred on 26 April 1986 (former USSR). An explosion in the Unit 4 reactor resulted in a catastrophic release of large quantities of radioactivity into the atmosphere. The explosion was caused by prompt neutron runaway because of violation of operating regulations and defects in the reactor design;

- In 1995 fire occurred at the fast sodium reactor "Monju" (Japan). It happened as a result of a non-radioactive sodium leak in the intermediate circuit pipeline and inadequate actions of personnel. It has taken 15 years to perform repair-and-renewal work;

- In 2011 the disaster at NPP Fukushima 1 (Japan) occurred because of the earthquake and following tsunami. Long blackout of BWR type reactors led to termination of removal of heat decay from the reactor cores and pools-storages of spent nuclear fuel. It was followed by meltdown of fuel and escape of radioactivity caused by steam discharge from the primary circuit and explosions of a hydrogen-air mixture generated due to the intensive steam-zirconium reaction. 
The initial events preceding these accidents are very dissimilar. They include personnel errors, technical failures, and extreme external impacts. However, there is a common cause of the severe consequences of all these accidents which is the result of releasing various types of potential energy accumulated in the coolant [11].

Safety and hazard are considered as interconnected concepts. The hazard from the RF is determined by two factors:

1) radiation potential accumulated, i.e., total radioactivity (more exactly, radiotoxicity) contained in the reactor facility;

2) probability of radioactivity release into the environment based on different initial events.

The first factor does not depend strongly on the RF type, because the total radioactivity contained in the RF, determined mainly by the amount of fission products, is associated primarily with the thermal power of the reactor and the duration of its operation at this power level, i.e., by energy production.

The second factor depends strongly on the RF type and is determined by reactivity margin, feedbacks, design features, and potential energy accumulated in the RF materials (thermal energy, coolant compression energy, chemical energy), which can be released due to different initial events. Therefore, the hazard associated with the RF (for identical power levels and operation time) will be determined by the second factor and, primarily, by the value of potential energy stored in the coolant.

Potential (non-nuclear) energy stored in the coolant is an inherent property of the material and cannot be changed. At the same time, the nuclear energy, which can be released under conditions of reactivity accidents, must be minimized as early as at the reactor design phase by limiting the reactivity margin, by the use of negative feedbacks, and by various engineering solutions, which exclude the possibility of insertion of positive reactivity exceeding the fraction from delayed neutrons.

Upgrade of safety for NPPs based on traditional type RFs requires an increase in the number of safety systems and defense-in-depth barriers, which reduce both the probability of the severe accidents happening and the weight of their consequences. When assessing this probability, failures of basic equipment, safety systems, protection barriers, and personnel errors are considered as random events.

However, because of the high complication of developing processes and lack of certain initial data required for calculation, there are many uncertainties in the results of safety substantiation by probabilistic analysis methods as applicable to severe accidents, their probability being very low $\left(\sim 10^{-6}\right.$ per reactor-year and less). Therefore, these results do not possess the necessary credibility value. Moreover, use of probabilistic analysis methods makes no sense in cases where we consider particular initial events, for example, acts of terrorism at the NPP, when safety systems, which are in standby mode, and protection barriers can be disabled deliberately, and after a certain series of actions the radioactivity release can achieve a disastrous value.

The issues of accounting for internal potential ("non-nuclear") energy, which can be released in events of abnormal external impacts, were studied earlier [12,13] in the analysis of RF safety. The importance of the analysis of such scenarios is verified by the fact that they have also been addressed by the IAEA [14]. This is owing to the fact that the RF, in which the potential energy is accumulated in the coolant in great amounts and can be released in an event of tightness failure in the primary circuit, could be used by terrorists as an instrument of political blackmail. 
The values of specific (per a volume unit) stored potential energy for different coolants $\mathbf{E}_{\text {pot }}$, which could be released in the event of severe accidents, are summarized in Table 1 (the hand-book data were used in computations).

Table 1. Comparison of different coolants according to values of stored potential energy.

\begin{tabular}{|c|c|c|c|}
\hline $\begin{array}{l}\text { Coolant } \\
\text { Parameters }\end{array}$ & $\begin{array}{c}\text { Water } \\
\mathrm{P}=16 \mathrm{MPa}, \\
\mathrm{T}=300^{\circ} \mathrm{C}\end{array}$ & $\begin{array}{c}\text { Sodium } \\
\mathbf{P}=\mathbf{0 . 1} \mathrm{MPa}, \\
\mathrm{T}=\mathbf{5 0 0}^{\circ} \mathrm{C}\end{array}$ & $\begin{array}{c}\text { Lead, LBC } \\
P=0.1 \mathrm{MPa}, \\
\mathrm{T}=500^{\circ} \mathrm{C}\end{array}$ \\
\hline $\begin{array}{l}\text { Maximum potential energy, } \mathrm{GJ} / \mathrm{m}^{3} \text {, } \\
\text { including: }\end{array}$ & $\sim 21.9$ & $\sim 10$ & $\sim 1.09$ \\
\hline Thermal energy & $\sim 0.90$ & $\sim 0.6$ & $\sim 1.09$ \\
\hline Including potential compression energy & $\sim 0.15$ & None & None \\
\hline $\begin{array}{l}\text { Potential chemical energy } \\
\text { of interaction }\end{array}$ & $\begin{array}{c}\text { With zirconium } \\
\sim 11.4 \\
\end{array}$ & $\begin{array}{c}\text { With water } \sim 5.1 \\
\text { With air } \sim 9.3\end{array}$ & None \\
\hline $\begin{array}{l}\text { Potential chemical energy of interaction } \\
\text { of hydrogen released with air }\end{array}$ & $\sim 9.6$ & $\sim 4.3$ & None \\
\hline $\begin{array}{l}\text { Potential energy of compression } \\
\text { and chemical energy * }\end{array}$ & $\sim 21$ & $\sim 9.4$ & None \\
\hline
\end{tabular}

* The last line of Table 1 presents the constituents of total potential energy, which can cause RF damage in an event of accident.

When analysing the consequences of potential energy release, we should keep in mind the following:

1) for water coolant, some amount of stored thermal energy can be converted into kinetic energy of steam expansion (assessment in Table 1 is performed for an adiabatic process) that can cause mechanical destruction to the equipment, and water evaporation can cause loss of core cooling. Moreover, in an event of severe accident while steam chemically interacts with zirconium, thermal energy and hydrogen will be released in large quantities. Hydrogen, in turn, is a high-rating type of hazard;

2) when sodium coolant becomes in contacts with air, the release of stored chemical potential energy can cause fire and, in an event of an unfavorable scenario, also loss of core cooling. When sodium coolant becomes in contact with water, thermal energy and hydrogen will be released in large quantities;

3) for heavy liquid metal coolants (lead-bismuth alloy, lead), the stored thermal potential energy cannot be converted into kinetic energy, there will be no essential release of energy in an event of coolant chemically becoming in contact with air, water, and structural materials, there is no loss of core cooling in an event of tightness failure in the gas system.

In an event of their release, the potential energy of compression and chemical energy stored in the coolant (for different coolants their values are given in the last line in Table 1) can result in accidents due to loss of coolant and termination of heat removal from the reactor core, damage of safety systems and protection barriers, and radioactivity escape into the environment.

For the risk of radioactivity release from different types of RFs to be at a similar, socially acceptable level, the number of safety systems and defense-in-depth barriers, which strongly determine the NPP technical and economical characteristics, can be reduced in the case of decreasing the 
potential energy accumulated in the RF, mainly in the coolant, whose selection determines the RF engineering design. At this point, it is important that the high safety level at a low value of potential energy stored in the coolant can be achieved, mainly, due to elimination of the causes of severe accidents, i.e., deterministically.

At the same time, the higher the value of potential energy stored in the RF coolant $\left(\mathbf{E}_{\mathbf{p o t}}\right)$, the higher the probability of severe accident $(\mathbf{P})$, all other conditions being equal. This is qualitatively shown in Figure 2. (The shape of the curve is not result of calculations. It demonstrates the trend only). All this emphasizes the importance of this parameter to be accounted for when developing the NPP design.

Figure 2. Qualitative dependence of the probability of severe accident (P, arbitrary units) for a value of potential energy stored in RF coolant $\left(\mathbf{E}_{\mathbf{p o t}}\right.$, relative units).

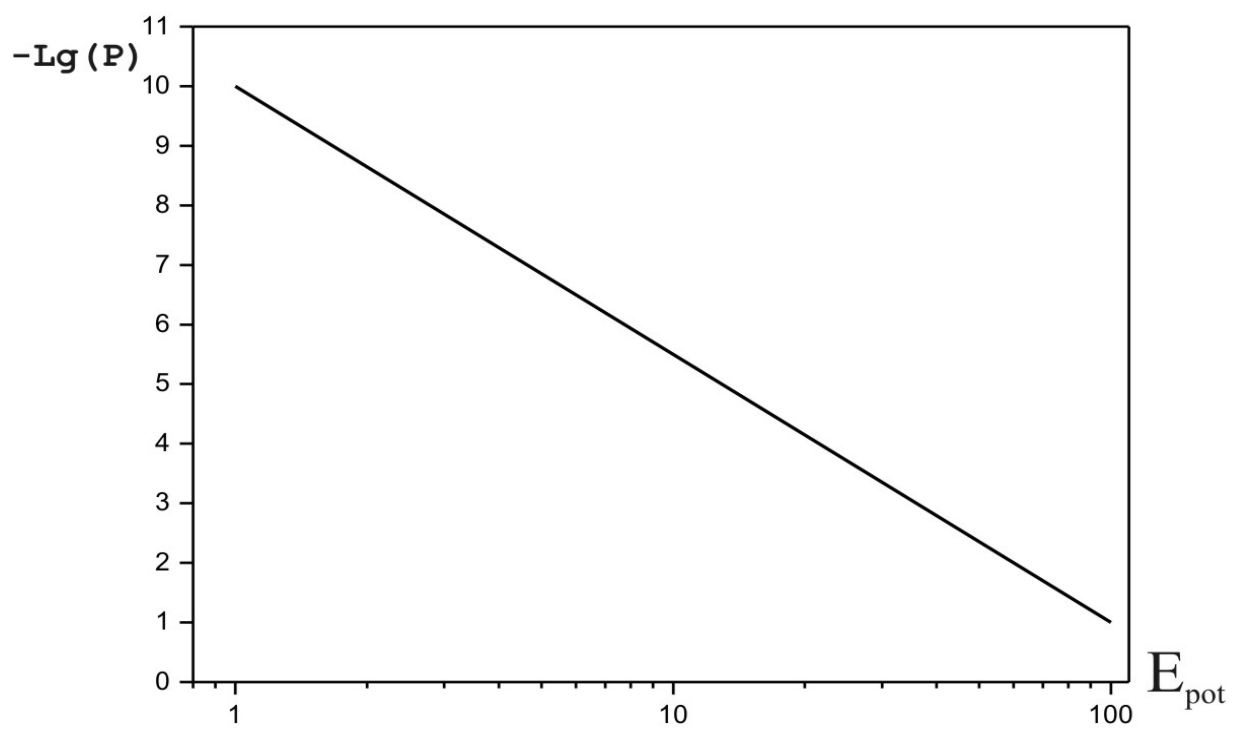

The potential energy stored in the coolant affects not only the safety characteristics but the NPP economic parameters as well. It is conditioned by the fact that for NPPs with traditional type reactors (with a high value of potential energy stored in the RF coolant), safety and economic requirements are in contradiction. The highlighted conflict appears as follows: when heightening the safety requirements, the NPP economic parameters deteriorate caused by the necessity to increase the number and efficiency of used safety systems and defense-in-depth barriers. A quality-based illustration of this situation is presented in Figure 3, where the cost $(\mathbf{C})$ of the NPPs with identical power is shown as a function of a regulated value of probability of the severe accident (P) for different values of potential energy $\mathbf{E}_{\text {pot }}$ stored in the RF coolant. (The shape of the curve is not result of calculations. It demonstrates trend only.)

Therefore, the most expedient way to upgrade the NPP safety and at the same time improve the economic characteristics is use of RFs, in which the value of stored potential energy is the lowest and in which the inherent self-protection and passive safety properties can be realized to the maximal extent. For example, this would be the RF based on modular fast reactor SVBR-100 with heavy liquid metal coolant-eutectic lead-bismuth alloy. 
Figure 3. Qualitative dependence of the NPP cost on regulated probability of a severe accident for different values of potential energy.

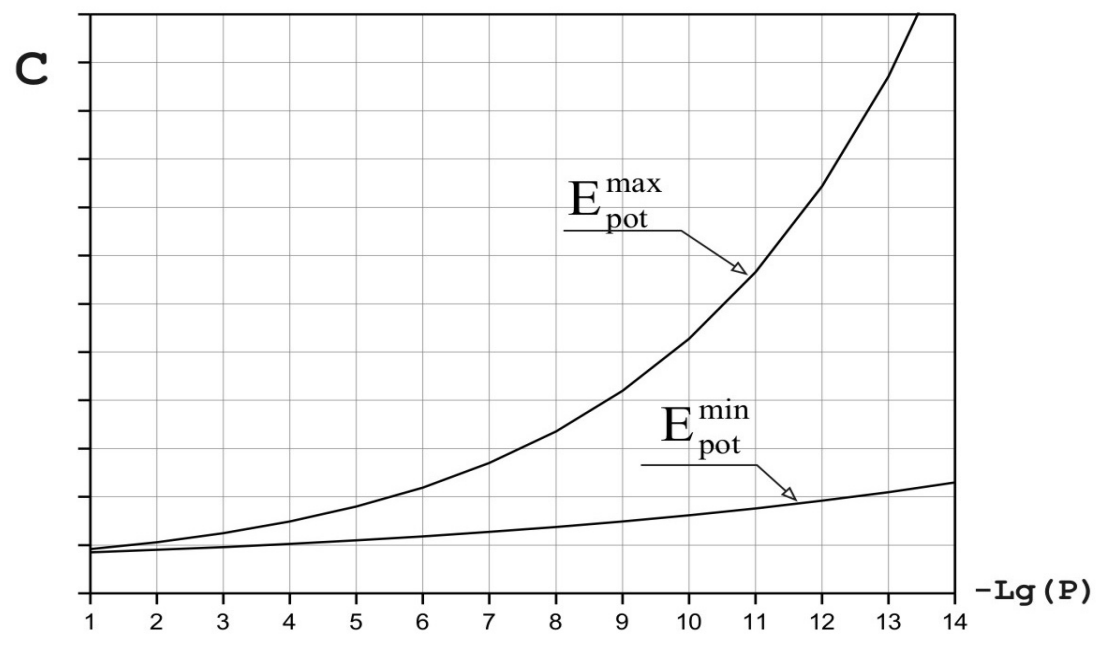

These RFs cannot amplify the external impacts. Therefore, the scale of damages will be only determined by the energy of the external impact, the exhaust of radioactivity being localized. Such types of RFs will possess the robustness properties, which will ensure their enhanced stability not only in events of single failures of the equipment and personnel errors, but also in events of malevolent actions, which is especially relevant for nuclear power (NP) development in developing countries where the threat of terrorism is very high. In an event of such a situation which occurred at NPP Fukushima, there would have been no radioactivity exhaust beyond the NPP fence.

\section{Basic Statements of the RF SVBR-100 Concept}

\subsection{Reactor Facility SVBR-100}

RF SVBR-100 has been designed as a standardized reactor facility of equivalent power of $\sim 100$ MWe for multi-purpose usage as a component of modular nuclear plants or as autonomous power-sources for regional nuclear power [15].

Features of the RF SVBR-100 are as follows:

1) A fast neutron reactor with $\mathrm{LBC}$ that is chemically inert to water and air, i.e., eutectic lead-bismuth alloy in the primary circuit. Boiling point of $\mathrm{LBC}$ is $1670{ }^{\circ} \mathrm{C}$, melting point of $\mathrm{LBC}$ is $123.5^{\circ} \mathrm{C}$.

2) An integral design of the reactor, in which the whole primary circuit equipment is mounted in a single strong vessel of the reactor monoblock (RMB). Valves and LBC pipelines are completely eliminated.

3) The primary circuit equipment is installed within the reactor monoblock with a safeguard casing.

4) A two-circuit scheme of heat removal and a steam generator (SG) with multiple circulation over the secondary circuit are used.

5) Natural circulation (NC) of coolants in the heat-removal circuits of the reactor monoblock is sufficient to ensure passive removal of heat from the reactor without dangerous over-heating of the core. 
6) The number of special safety systems operating in a standby mode is noticeably reduced.

7) The basic components of the reactor monoblock and reactor facility are designed as separate modules. At this point, an opportunity for their replacement and repair is ensured.

8) On ending the lifetime, fuel unloading will be performed at once, cassette-by-cassette, and fresh fuel will be loaded as a single cartridge (new core). Core layout is presented in Figure 4.

Figure 4. Reactor core layout.

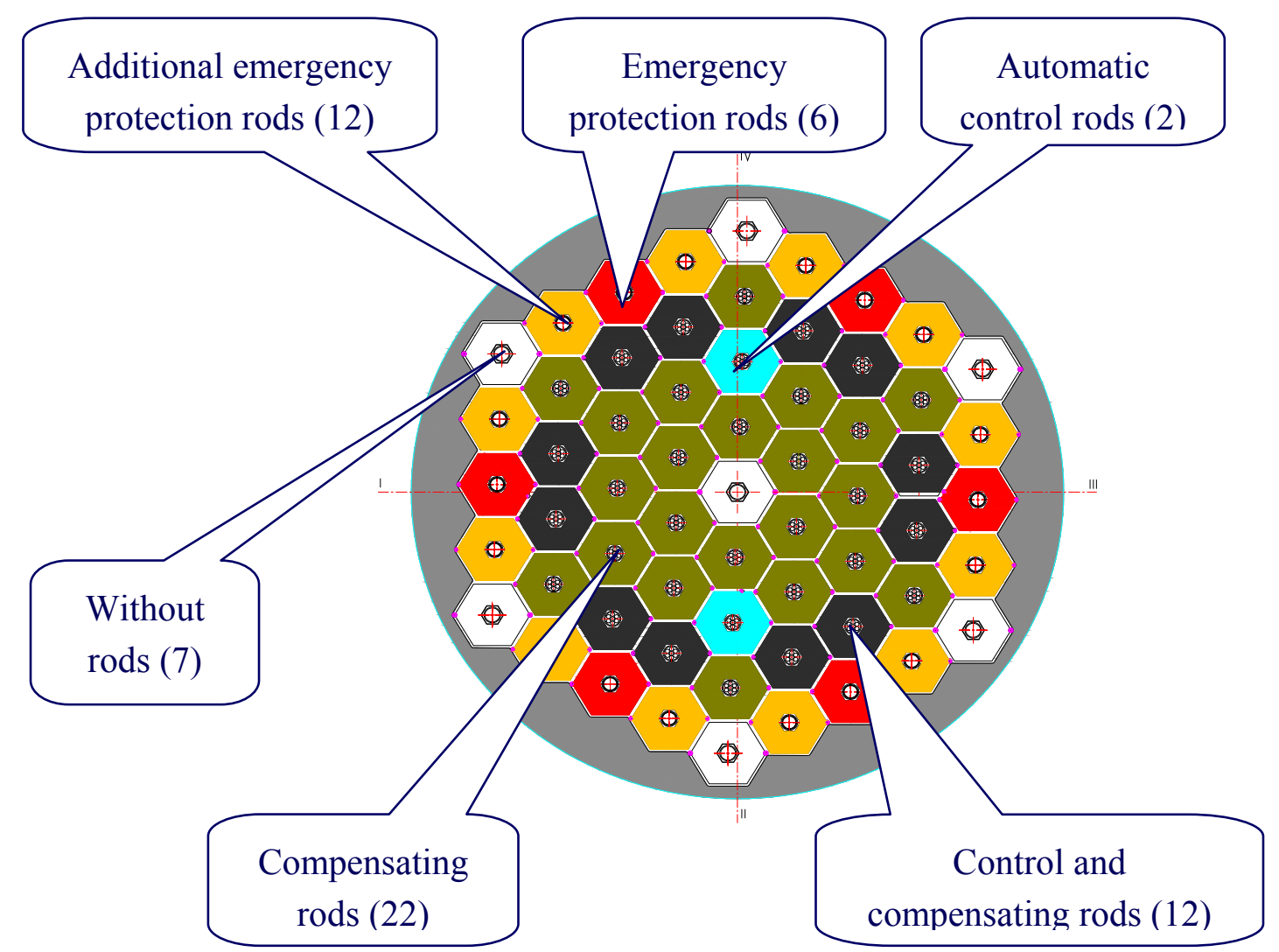

9) There is an opportunity to use different kinds of fuel (uranium oxide, MOX fuel, nitride fuel) without change of the reactor design. While operating the reactor using MOX fuel and nitride fuel, the core breeding ratio (CBR) exceeds 1 . In the closed fuel cycle it ensures operation in a mode of self-providing fuel. Fuel reliability has been proved for the fuel based on uranium oxide that will be used in FOAK prototype-reactor SVBR-100 but for other kinds of fuel the additional R\&D needed has to be carried out.

10) Repair of the primary circuit equipment and refueling can be performed without LBC draining by maintaining the liquid state of LBC due to core residual heat or heating system operation.

The reactor monoblock and arrangement of the RF SVBR-100 equipment are presented in Figure 5, Figure 6. The basic parameters of RF SVBR-100 are presented in Table 2. 
Figure 5. Reactor monoblock.

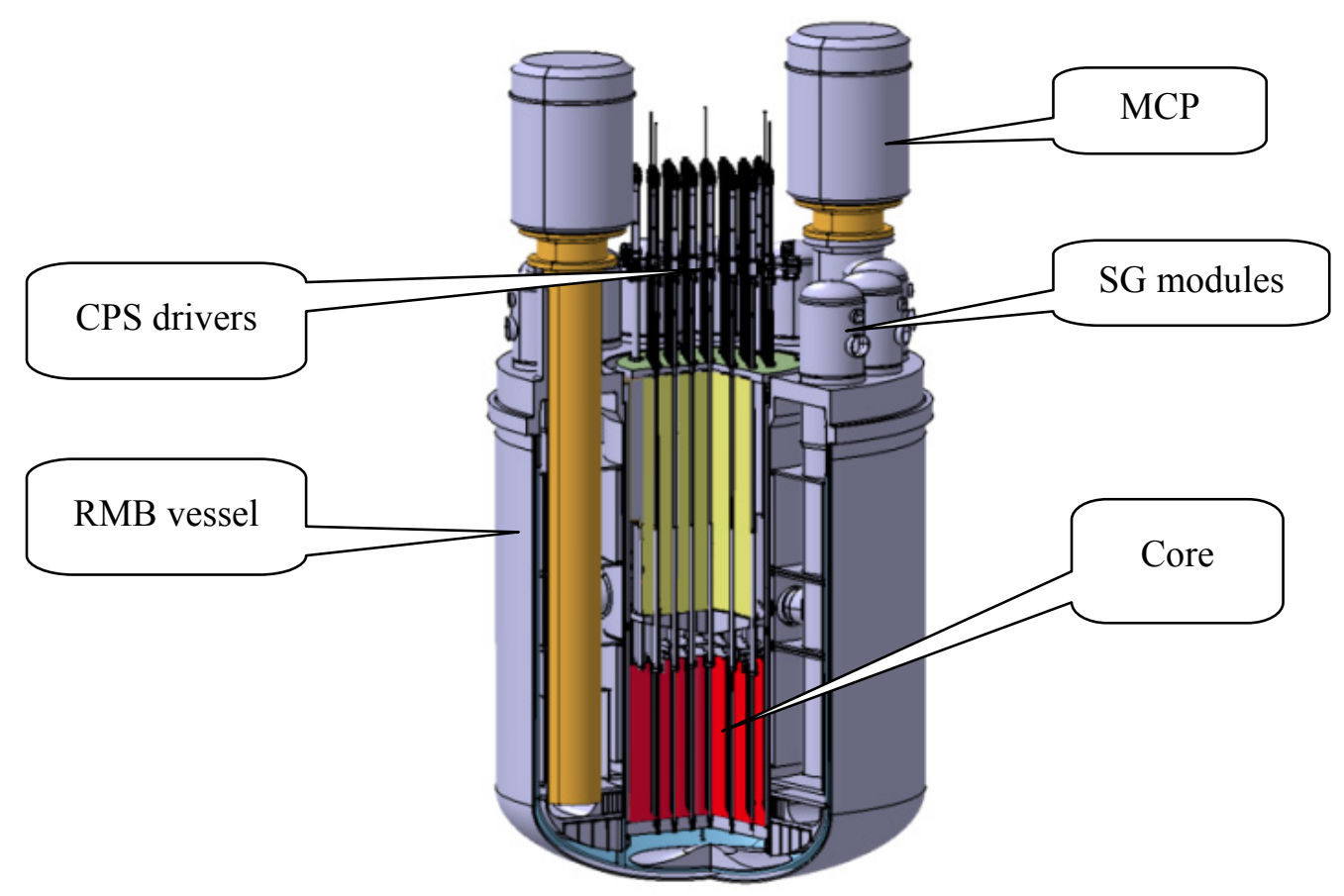

Figure 6. Equipment arrangement in RF SVBR-100.

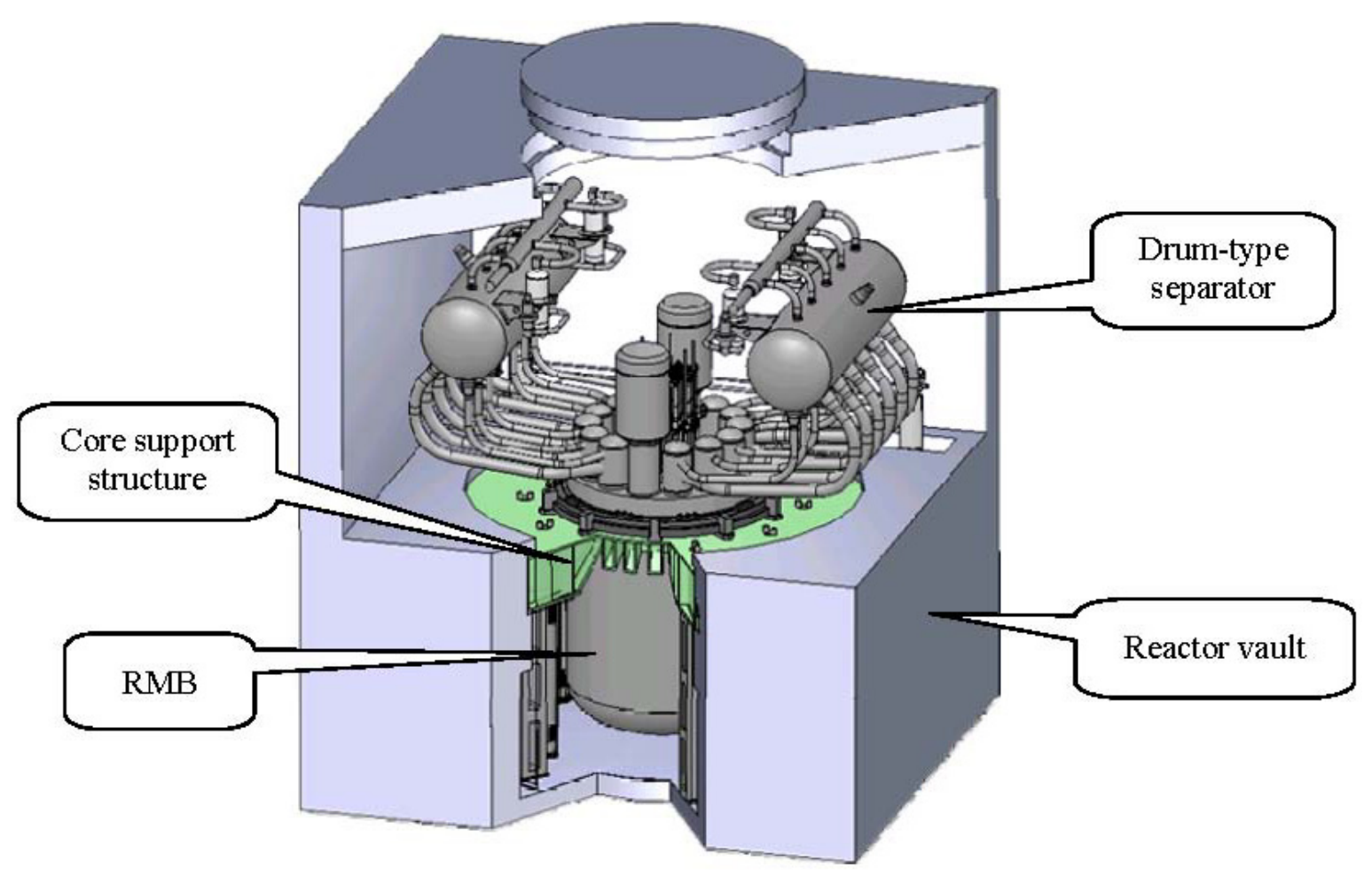


Table 2. Basic parameters of RF SVBR-100 (basic variant).

\begin{tabular}{lc}
\hline Parameter & Value \\
\hline Set up power (thermal/electric), MW & $280 / 101.5$ \\
Steam-producing rate, $\mathrm{t} / \mathrm{h}$ & 485 \\
Steam parameters: pressure, $\mathrm{MPa} /$ temperature, ${ }^{\circ} \mathrm{C}$ & $6.7 / 275$ \\
Flow rate of the primary circuit coolant, $\mathrm{kg} / \mathrm{s}$ & 12800 \\
Temperature of the primary circuit coolant: - inlet/outlet, ${ }^{\circ} \mathrm{C}$ & $490 / 340$ \\
Fuel $\left(\mathrm{UO}_{2}\right.$ ): $\mathrm{U}-235$ loading, $\mathrm{kg} / \mathrm{U}-235$ average enrichment, $\%$ & $\sim 1480 / 16.3$ \\
Change of reactivity during the lifetime, $\%(\$)$ & $-3.74(-5.72)$ \\
Core dimensions: $\mathrm{D} \times \mathrm{H}$ (diameter $\times$ height), $\mathrm{m}$ & $1.8 \times 0.9$ \\
Average volumetric power density of the core, $\mathrm{kW} / \mathrm{dm}^{3}$ & 160 \\
Average linear load of the fuel element, $\mathrm{kW} / \mathrm{m}$ & $\sim 25.7$ \\
The number of fuel elements & 12078 \\
The number of CPS rods & 50 \\
Core lifetime, thousands of full power hours & $\sim 50$ \\
Time interval between refueling, years & $\sim 7-8$ \\
The number of steam generator modules & 12 \\
The number of MCPs & 2 \\
MCP head/electromotor's power, $\mathrm{MPa} / \mathrm{kW}$ & $0.7 / 690$ \\
LBC volume in the primary circuit, ${ }^{3}$ & $\sim 25$ \\
Dimensions of the reactor monoblock vessel: $\mathrm{D} \times \mathrm{H}($ diameter $\times$ height $), \mathrm{m}$ & $4.41 \times 7.85$ \\
\hline
\end{tabular}

\subsection{Use of Real Operating Experience and Conservative Approach}

The proposed reactor technology is based first of all on forty-year experience of development and operation of LBC cooled RFs at the NSs and ground facilities-prototypes.

A conservative approach was used to design RF SVBR-100. This approach presumed that the technical solutions borrowed or scaled with small coefficients from the NS RFs were used in the reactor design. These technical solutions have been verified by the operating experience of other RFs.

The conservative approach includes use of mastered mode parameters of the primary and secondary circuits and orientation to the existing fuel infrastructure and technological opportunities of machine building enterprises.

That approach makes it possible to reduce considerably the technical and financial risks, lessen the number of possible errors and failures, which are typical while implementing the innovative nuclear technologies, and diminishing the scale, execution schedule and cost of the R\&D.

\subsection{Inherent Self-Protection and Passive Safety of the RF}

The main effect in providing a high safety level of the SVBR-100 RF (inherent self-protection and assured elimination of severe accidents) is achieved due to use of the fast-neutron reactor, heavy liquid-metal coolant and integral design of the reactor and has been verified by realized computations and development works [16].

The reactor possesses a negative void reactivity effect and negative feedbacks, and the efficiency of the strongest absorbing rod does not exceed 1\$. This coupled with technical realization of the control 
and protection system (CPS) eliminates prompt neutron runaway of the reactor. This covers all types of fuel mentioned in paragraph 5.1 (point 9 in the list) [17].

The high boiling point of coolant heightens the reliability of heat removal from the core, and improves safety due to lack of the heat transfer crisis. This is also coupled with a provided safeguard casing of the monoblock, that eliminates loss of coolant accidents (LOCA) and high pressure radioactive exhausts.

Low pressure in the primary circuit reduces the risk of its failure. It enables the thickness of the reactor vessel's walls to be reduced and diminishes the limitations imposed on the rate of temperature change according to the thermal-cycling strength conditions.

The RF components do not contain materials releasing hydrogen as a result of thermal and radiation effects and chemical reactions with coolant, water and air. Therefore, in an event of tightness failure in the primary circuit the likelihood of chemical explosions and fires is virtually eliminated.

Inherent self-protection properties of the RF make it possible to couple realization of most of the safety functions and the normal operating functions of the RF.

The circulation scheme of LBC provides for elimination of water/steam ingress into the core in an event of SG leak due to effective separation of steam on a free LBC level in the monoblock.

At this point, the safety systems do not contain elements, in which actuation can be blocked in an event of failure or under impact of human factors:

- removal of heat decay is provided passively by natural circulation of LBC in the primary circuit and steam-water in the secondary circuit. This is realized by transferring heat from cooling condensers (which are connected to separators) immersed into water in tanks of passive heat removal systems (PHRS) and further due to water boiling in tanks, with steam removal to the atmosphere. (This represents a grace period of about three days without exceeding the allowed temperature limits);

- in an event of guillotine rupture in a single tube or termination of operation of the gas system condenser, localization of the SG leak is also provided passively while increasing steam pressure in the gas system over $0.5 \mathrm{MPa}$. This is provided by bursting of the preserve membrane and discharging steam into the bubbling device. (Operating experience has revealed that in an event of a small leak in the SG, the RF does not need to be shut down at once);

- when the LBC temperature is increased over the allowed value, the rods of the additional emergency protection system, which are mounted in "dry" channels and do not have drivers on the reactor lid, actuate passively by gravity due to fusible locks made of the alloy with a corresponding melting temperature and hold the rods in an upper position at normal temperature modes.

As computations have revealed, the safety potential of the SVBR-100 RF is characterized by the following features. No reactor runaway, explosion and fire occurs, even when there is superposition of such postulated initial events as damage of the protective shell, damage of the reinforced concrete overlapping the reactor, tightness failure in the primary circuit gas system with direct contact between a LBC surface in the reactor monoblock and atmospheric air, and total "blackout" of the NPP. Radioactivity exhaust into the environment does not reach values requiring population evacuation 
beyond the NPP fence. According to the assessments, the probability of severe damage of the core is much lower than the value specified in the regulatory documentation.

One of the basic factors determining a high safety level is a low value of potential energy stored in the coolant.

This enables discussion not only about RF tolerance to equipment failures and personnel errors and their multiple superposition but also about tolerance to malevolent actions when all special systems operating in a standby mode have been intentionally disabled.

\subsection{Modular Structure of the Nuclear Steam Supplying System of the Power-Unit}

The important feature of the considered NPT is use of small power reactors $(\sim 100 \mathrm{MWe})$ as functionally completed steam-producing modules. On the basis of these modules it is possible to construct nuclear power-units of any power divisible by $100 \mathrm{MWe}$ and for different purposes.

This untraditional approach to making the nuclear steam supplying system (NSSS) of the power-unit is economically effective in the case when the RF possesses developed inherent self-protection and passive safety properties and does not require a large number of special safety systems.

In this case the loss of scale of economy is compensated by the following: (1) absence of many special safety systems operating in a standby mode, which are necessary for traditional types of reactors with the purpose to reduce the probability of severe accidents and lessen the weight of their consequences; (2) high serial production of "standard" reactor modules; (3) complete factory manufacture of the basic components of the RF-a reactor monoblock, in which all primary circuit equipment is installed; (4) reduction of the duration of the investment cycle.

Due to a modular structure of the nuclear steam supplying system (NSSS) of the power-unit it is possible:

1) to provide higher reliability (tolerance to failures of the power-unit being a system composed of separate RFs) and safety (to reduce the potential radiation risk) as compared with a power-unit based on a single reactor of large capacity;

2) not to organize a large capacity reserve power-source for regional NPPs in the areas of distributed power supply;

3 ) to provide a loading factor (LF) of not less than $90 \%$ due to long reactor operation without refueling. LF will be only determined by reliability factors of the turbine installation. When each $\mathrm{RF}$ is shut down for refueling or maintenance, the power-unit's capacity is reduced much less compared with that of the power-unit based on a single reactor of large unit capacity;

4) to organize production of reactor monoblocks in large quantities (tens of monoblocks annually) and continuous work load of engineering factories. Thus, the manufacturing costs will be considerably reduced. As fabrication of the reactor monoblock of the RF does not require unique engineering equipment as for high pressure vessels of thermal reactors, there is an opportunity to form a competitive market of producers;

5) to use the standard designs for different capacity power-units and factory production-line methods for their assembly and construction. Along with high quantity production of RFs, these assure reduction in the schedule and cost of power-units construction to values, which can be 
compared to similar parameters of modern thermal power plants (TPP) while the cost of produced electricity is much lower;

6) to locate modular small and medium-sized NPPs in the centers of power consumption. Therefore, the expenditure for construction of high-voltage lines will be eliminated;

7) to provide an opportunity of phase-by-phase implementation of the power-unit in operation with gradual raising of power capacity as the assembly, start-up and adjustment works for the regular module have been completed. Thus, the pay-back term of the capital investments can be reduced due to earlier output of production and earlier start of credit repayment compared to a power-unit based on a large capacity reactor.

These all improve the consumer characteristics of RF SVBR-100.

The NSSS modular structure and shipment of factory-ready modules assures reduction of the investment cycle of NPP construction making it extremely viable for technical and economic parameters of the NPP, which can then be closer to those of steam-gas plants with short investment cycles. Therefore, the financial risks can be considerably reduced. Control of the modular NSSS is carried out by one operator using the common power master unit.

On expiration of the RF lifetime (50-60 years) and unloading the spent nuclear fuel and LBC, the basic RF element-reactor monoblock-will be dismantled and placed in a storage of solid radioactive waste. A new reactor monoblock will be installed instead. The other elements of the RF and power-unit can be dismantled and replaced as well, i.e., the renovation can be performed. At this point, the lifetime of the modular NPP will be limited by that of the concrete construction structures and can be expanded up to 100-120 years while the costs are much less compared to those required for construction of the new power-unit. When the power-unit has been completely decommissioned, practically no radioactive materials will remain in the NSSS building after dismantling the reactor monoblocks. Thus the cost of decommissioning will be considerably reduced.

\subsection{Flexible Fuel Cycle}

The design of the SVBR-100 RF allows it to operate using different types of fuel and in various NFC, without change to the RF design or deterioration of safety characteristics [17].

During the next decades, at existing low costs of uranium and its enrichment, the most economically effective fuel type will be the mastered oxide uranium fuel with operation in the open NFC with postponed SNF reprocessing.

Changeover to the mixed uranium-plutonium fuel and closed NFC, with CBR $\geq 1$ will be economically effective when the cost of natural uranium increases. At this time, the expenditures for construction of factories for SNF reprocessing and re-fabrication of fresh fuel with plutonium, and their operating costs must be less than the corresponding costs of natural uranium, its enrichment, manufacture of fresh uranium fuel and long-term SNF storage.

The expenditure caused by changeover to the closed NFC will be lower, if plutonium extracted from self supplied SNF of uranium loads is used in fabrication of the first MOX fuel loads. The content of plutonium in this SNF is higher by an order of magnitude than the plutonium content in the SNF from the thermal reactors, which is usually considered as a source of plutonium for FR launching. Due to the fact that the scope of SNF reprocessing per 1 ton of plutonium is inversely 
proportional to the content of plutonium in the SNF, the cost of plutonium extraction will be correspondingly lower.

As FRs operating in the open NFC by using uranium fuel consume much more natural uranium in comparison with thermal reactors, and at the expected high paces of nuclear power development the cheap resources of natural uranium will be exhausted quickly, it is necessary to assess the period required for changeover to the closed NFC with use of self supplied SNF of uranium loads.

As computations have revealed, for reactor SVBR-100 it is possible to begin changeover to the closed NFC after the second lifetime i.e., in 16 years (see Figure 7). At this time, during the first 16 years the consumption of natural uranium calculated for $1 \mathrm{GWe}$-year will be 5670 tons (when operated by using oxide uranium fuel, $\mathrm{CBR}=0.84$ ). During the 60 years of the RF service lifetime, the consumption of natural uranium calculated for $1 \mathrm{GWe}$ will be by $30 \div 40 \%$ lower than its consumption by WWER-1000 during that time.

Figure 7. Comparative annual consumption of natural uranium.

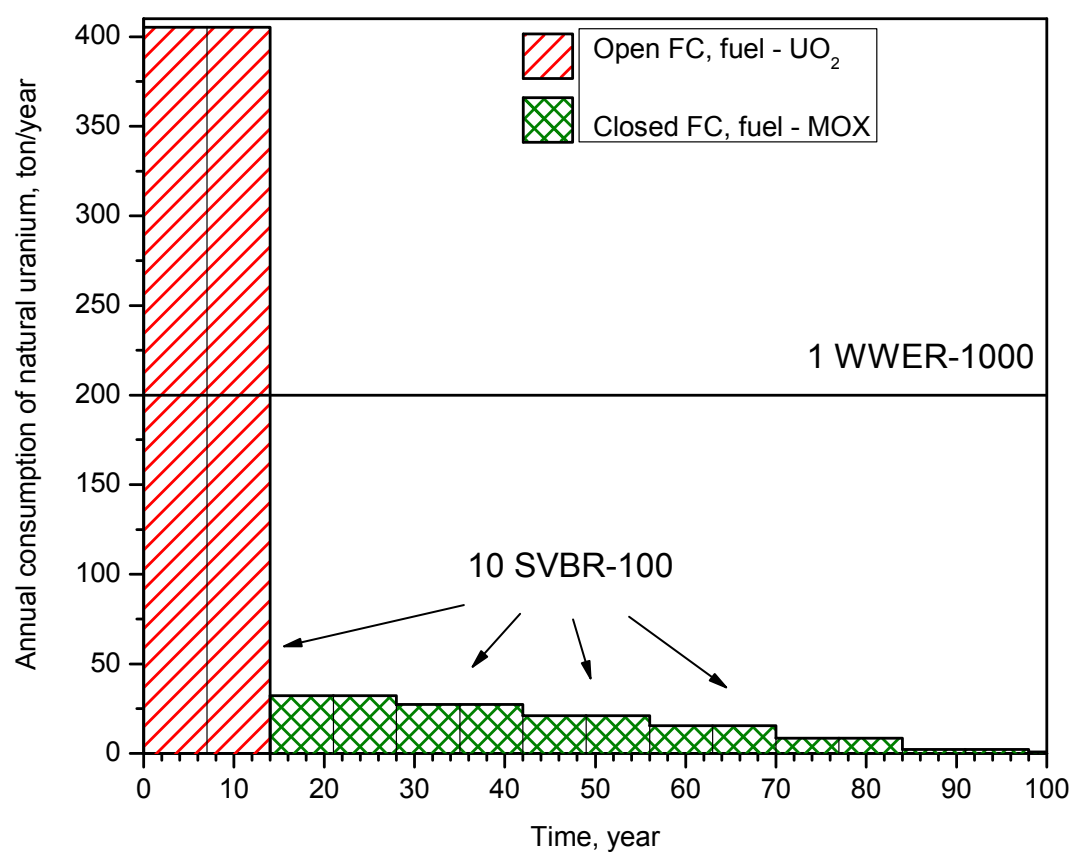

Further FR operating in the closed NFC prior to reaching the equilibrium refueling mode will be realized practically without consumption of natural uranium [18]. As makeup fuel, the LWR SNF without chemical reprocessing may be utilized in this closed NFC (similar to the DUPIC-technology) [19].

SNF storage prior to reprocessing is presumed to be realized as follows. After the spent fuel sub-assembly (FSA) has been extracted from the reactor, it is installed in a penal, in which lead has been previously heated in an electric furnace above its melting point. Then the penal is sealed and transported to the "dry" SNF storage with natural convection air-cooling. At this, lead in the penal solidifies gradually and forms an additional protection barrier. Therefore, multi-barrier protection is formed by way of radioactivity release from the stored SNF.

When operating in the closed NFC, handling the fission products does not provide for their transmutation because of the low efficiency of the process. Taking into account that the half life of the 
majority of fission products does not exceed 30 years (except for technetium—99, iodine-129, cesium-135, and some others), it is supposed that after extraction from SNF they will be vitrified and placed into a "dry" controlled storage for $\sim 300$ years. After cooling, their activity will be determined by long-lived nuclides of technetium, iodine and cesium. It is presumed these vitrified fission products will be disposed in deep geological formations while providing multi-barrier protection. Instead of vitrifying a "synrock"-technology can be used after its advantages have been verified. This method of handling the fission products eliminates radioactivity release into the environment.

Handling the minor actinides (MA) (neptunium, americium, curium) presumes that they will not be released beyond the fuel cycle (except for very low losses at the stage of RAW chemical reprocessing) as they are well fissionable in a hard neutron spectrum of FRs and their concentration achieves saturation condition very quickly. To estimate the environmental impact caused by the NFC of reactor SVBR-100, a value of specific radiotoxicity of formed MA and long-lived fission products (technetium-99, iodine-129, cesium-135) as a function of produced electricity was taken as a criterion. In the case where this value is decreasing with energy production, the NFC environmental effect should be considered as a "friendly" one. The radiotoxicity standard is adopted as the volume of water required to dilute the given quantity of radionuclides to the concentrations, when specific radioactivity of the obtained solution meets sanitary requirements for drinking water. Specific radiotoxicity is determined as SNF radiotoxicity for the given produced energy divided by the value of produced energy.

The analysis of the obtained results (see Figure 8) has revealed the environmental-"friendly" effect of the NFC of reactor SVBR-100 as specific radiotoxicity of long-lived RAW intended for final disposal decreases while the value of cumulative produced energy increases. This is caused by the fact that the hard neutron spectrum in the reactor facilitates efficient burning of MA.

Figure 8. Dependence of specific radiotoxicity on produced energy.

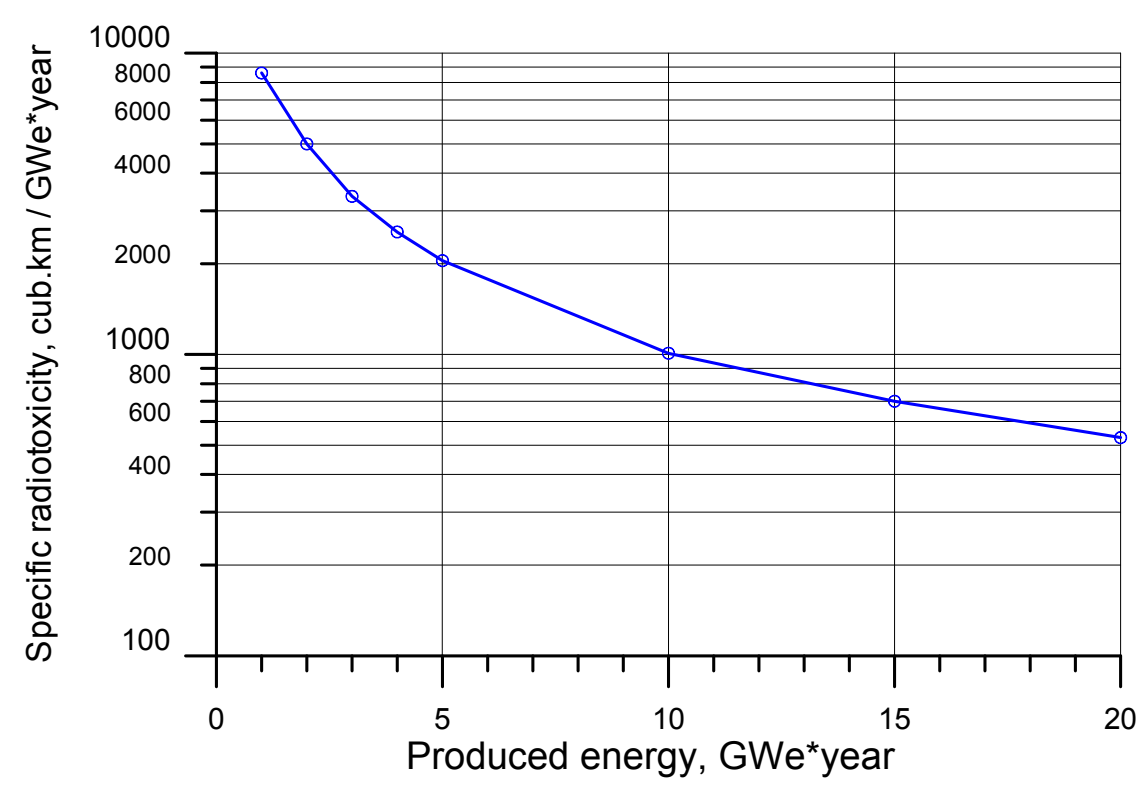


Adaptability of the SVBR-100 reactor relative to the fuel type and fuel cycle makes it possible to realize a timely and gradual changeover to the closed NFC, which will be economically justified. Simultaneously, the problem of radiation-equivalent burial of long-lived RAW will be solved.

\subsection{Proliferation Risk Decreasing}

The solution to the problem of non-proliferation can be only achieved by coupling both technological and political measures. The relationship of those measures will be different for nuclear and non-nuclear countries. During the recent decades all nuclear countries, which are members of the "Nuclear Club" and legally possess nuclear weapons, have solved this problem successfully, using measures of physical protection, accounting, control and safeguard. For this reason, the additional measures of technological maintenance of non-proliferation will be justified in the case where they do not lower NP competitiveness.

When NPPs are used in developing countries, additional measures of technological maintenance for non-proliferation should be implemented, along with political measures and international control.

Duration of the fuel lifetime makes it possible to perform refueling not more often than once in an eight year period. The special heavy equipment is not shipped to the user-country and refueling is performed in the supplier-country under the supervision of IAEA.

At this point, technological support for non-proliferation is also assured by the following features. When uranium fuel is fabricated, uranium enriched less than $20 \%$ will be used. At the stage of SNF reprocessing, $2 \%$ of fission products built-up in the SNF and all minor actinides (MA) will remain in the re-fabricated fuel, except for curium that is released and kept to decay into plutonium with return to the fuel cycle. Handling this fuel requires special technological equipment, to make it easy to account and control the fuel movements. Moreover, in the reactor there are no breeding zones, in which plutonium for weapons can be built-up.

When NPPs are used in developing countries, shipment of fresh fuel and acceptance of SNF for storage and reprocessing should be realized on the basis of nondiscrimination by International Centers for Nuclear Fuel Cycles in accordance with initiatives of the Russian and USA presidents.

\subsection{High Potential for Improvement}

The innovative Project of the NPP with RF SVBR-100 predetermines a high potential for further improvement that will be realized as the corresponding R\&D have been accomplished and operating experience has been gained.

In particular:

- Increasing the LBC temperature at the reactor outlet while increasing the value of maximal temperature of the fuel element's cladding from 600 to $650{ }^{\circ} \mathrm{C}$ (these are all necessary backgrounds) will provide (as the computations have revealed) growth of the reactor thermal power by $10 \%$ without considerable change of the reactor design.

- Use of the once-through SG generating super-heated steam assures the efficiency of the thermodynamic cycle will be heightened by about $10 \%$, capital costs will be lowered, and RF design will be simplified. 
- Use of dense nitride fuel can provide increase of the reactor lifetime from 7-8 years for oxide uranium fuel to 15 years (the operability of fuel elements has been verified) and correspondingly reduce fuel consumption.

\subsection{Commercialization Concept}

For the purpose of commercialization of SVBR technology and justification of technical and economic parameters, it has been scheduled to construct an experimental-industrial power-unit with RF SVBR-100.

It should be highlighted there will be only a one-time expenditure for the $R \& D$ and construction of the experimental-industrial power-unit (prototype) as on the basis of the tested standardized reactor module it is possible to construct nuclear power-units of different capacities and purpose without carrying out the supplementary R\&D.

The experimental-industrial RF equipped with accessory sensors and devices can be used for demonstration of inherent self-protection and passive safety properties of the RF in the controlled conditions for simulating all the possible super-positions of equipment failures, personnel errors and malevolent actions.

\section{Conclusions}

1. The most expedient way to upgrade the NPP safety and at the same time improve the economic characteristics is use of RFs, in which the value of stored potential energy is the lowest and inherent self-protection and passive safety properties can be realized to the maximal extent.

2. These RFs cannot amplify external impacts, therefore, the scale of damages will be only determined by external impact energy, with exhaust of radioactivity being localized. Such types of RFs will possess the robustness properties to assure their enhanced stability not only in events of single failures of the equipment and personnel errors, but also in events of malevolent actions. This is especially important for development of nuclear power in developing countries with a high threat of terrorism.

3. The innovative nuclear power technology based on multi-purposed standardized modular fast reactors with chemically inert lead-bismuth coolant i.e., SVBR-100, which possess developed inherent self-protection and passive safety properties (such as deterministic elimination of severe accidents), will assure a high level of social acceptability for these reactors and widen the area of their application in the NP. Due to the low amount of potential energy stored in the coolant, the radiation consequences of a severe accident such as that at NPP Fukushima 1 are deterministically eliminated (on the assumption that the initial events are identical).

4. The modular structure of the power-unit's NSSS provides an opportunity to changeover to advanced technologies of standard design for different capacity power-units on the basis of series factory-manufacture of standardized reactor modules and changeover to production-line methods for their assembly. This will make possible considerable reduction of the schedule period required for NPP construction as well as to provide technical maintenance of reactor modules on a servicing base. Thus, the number of operating personnel and corresponding expenditures will be reduced. 
5. Federal target program "New Generation Nuclear Power Technologies for 2010-2015 and Future Trends up to 2020" stipulates the construction of a first-of-a-kind power unit: experimental-industrial power-unit.

The Project is being realized within the framework of state-private partnership with joint venture OJSC "AKME-Engineering" established on a parity basis by the State Atomic Energy Corporation "Rosatom" and the Limited Liability Company "EuroSibEnergo".

The first of a kind power-unit with RF SVBR-100 will be commissioned in 2017 in Dimitrovgrad (Ulyanovsk region). Bird's eye view of experimental-industrial prototype SVBR-100 is shown in Figure 9.

Figure 9. Bird's eye view of experimental-industrial prototype SVBR-100.

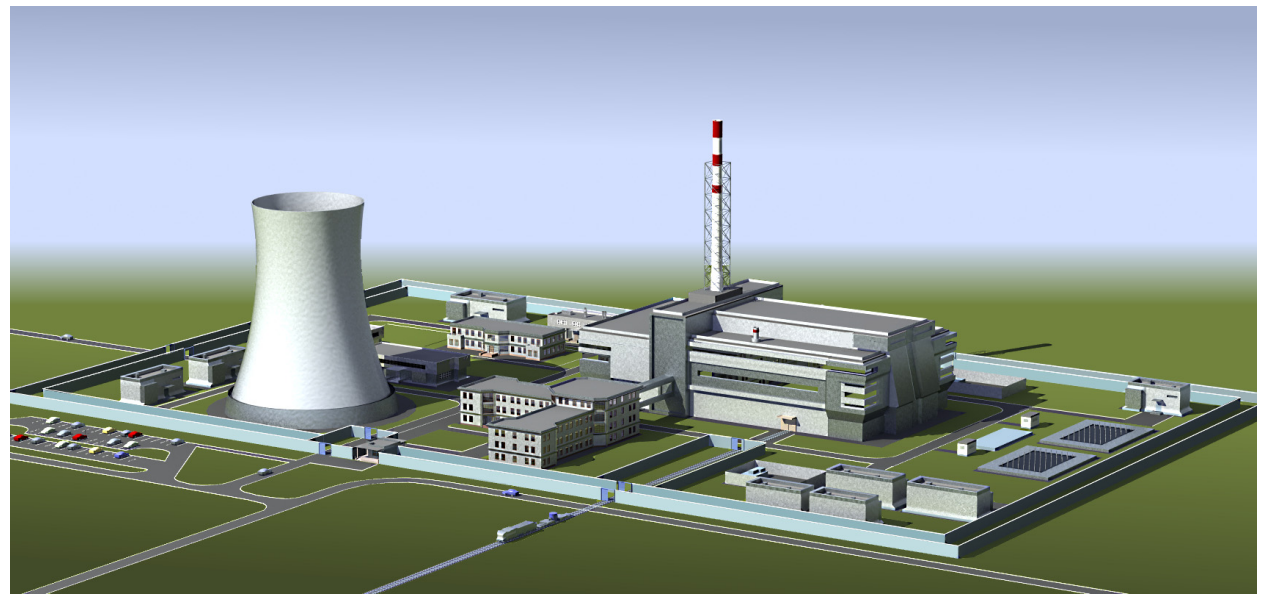

\section{Acknowledgments}

The authors would like to thank SSC RF-IPPE employee S. V. Budarina for the assistance in preparation of the present Paper.

\section{References}

1. International Atomic Energy Agency (IAEA). Guidance for the Evaluation of Innovative Nuclear Reactors and Fuel Cycles: Report of Phase $1 A$ of INPRO; IAEA-TECDOC-1362; IAEA: Vienna, Austria, 2003.

2. Zrodnikov, A.V.; Toshinsky, G.I.; Stepanov, V.S.; Komlev, O.G.; Stepanov, V.S.; Klimov, N.N.; Generalov, V.N.; Kopytov, I.I.; Krushelnitsky, V.N. Innovative nuclear technology based on modular multi-purpose lead-bismuth cooled fast reactors. Prog. Nuclear Energy 2008, 50, $170-178$.

3. Zrodnikov, A.V.; Toshinsky, G.I.; Dragunov, Y.G.; Stepanov, V.S.; Klimov, N.N.; Kopytov, I.I.; Krushelnitsky, V.N.; Yermakov, N.I.; Kornienko, A.G. Lead-Bismuth Reactor Technology Conversion: From Nuclear Submarine Reactors to Power Reactors and Ways to Increase the Investment Attractiveness of Nuclear Power Based on Fast-Neutron Reactors. In Proceedings of IAEA International Conference "Fifty Years of Nuclear Power-The Next Fifty Years", Obninsk, Russia, 27 June-2 July 2004. 
4. Leypunsky, A.I. Fast Neutron Systems. In Selected Papers. Reminiscence; Naukova Dumka: Kiev, Ukraine, 1990; p. 62.

5. Pankratov, D.V.; Yefimov, Y.I.; Toshinsky, G.I.; Ryabaya, L.D. Analysis of Polonium Hazard in Nuclear Power Installations with Lead-Bismuth Coolant. In Proceedings of International Congress on Advances in Nuclear Power Plants (ICAPP'05), Seoul, Korea, 15-19 May 2005.

6. Wiggs, L.D.; Cox-De Vore, C.A.; Voelz, G.L. Mortality among a Cohort of Workers Monitored for Po-210 Exposure: 1944-1972 y.y. Epidemiology Section Occupational Medicine Group; Health Physics-Los Alamos National Laboratory: Los Alamos, NM, USA, 1991; Volume 61.

7. ARMZ Uranium Holding Co. (AtomRedMetZoloto). The Analysis of Bismuth Mineral Resources in Russia, CIS and in the World; Report; ARMZ Uranium Holding Co. (AtomRedMetZoloto): Moscow, Russia, 2000.

8. Masakazu, I. A Conceptual Design Study on Various Types of HLMC Fast Reactor Plant. In Proceedings of Lead-Bismuth Technology International Meeting, OEC/JNC/Japan, O-Arai, Japan, 12-14 December 2000.

9. Gromov, B.F.; Grigoriev, O.G.; Dedoul, A.V.; Toshinsky, G.I.; Stepanov V.S.; Nikitin, L.B. The Analysis of Operation Experience of Reactor Installations Using Lead-Bismuth Coolant and Accidents Happened. In Proceeding of the Conference "Heavy Liquid Metal Coolants in Nuclear Technology” (HLMC-98), Obninsk, Russia, 5-9 October 1998; Volume 1, pp. 63-69.

10. Gromov, B.F.; Orlov, Y.I.; Martynov, P.N.; Gulevsky, V.A. The Problems of Technology of the Heavy Liquid Metal Coolants. In Proceeding of the Conference "Heavy Liquid Metal Coolants in Nuclear Technology” (HLMC-98), Obninsk, Russia, 5-9 October 1998; Volume 1, pp. 87-100.

11. Toshinsky, G.I.; Komlev, O.G.; Tormyshev, I.V.; Danilenko, K.Y. Effect of Potential Energy Stored in Reactor Facility Coolant on NPP Safety and Economic Parameters. In Proceedings of International Congress on Advances in Nuclear Power Plants (ICAPP 2011), Nice, France, 2-5 May 2011.

12. Gat, U. The Ultimate Safe (U.S.) Reactor. In Proceedings of ICENES-4, Madrid, Spain, 1987; World Sci. Publ. Co.: Madrid, Spain, pp. 584-595.

13. Novikov, V.M.; Slessarev, I.S.; Alekseyev, P.N.; Ignatyev, V.V.; Subbotin, S.A. Nuclear Reactors of Enhanced Safety. The Analysis of Conceptual Designs; Energoatomizdat Publishers: Moscow, Russia, 1993; p. 52.

14. International Atomic Energy Agency (IAEA). Advanced Nuclear Plant Design Options to Cope with External Events; IAEA-TECDOC-1487; IAEA: Vienna, Austria, February 2006. Available online: http://www-pub.iaea.org/MTCD/publications/PDF/te_1487_web.pdf (accessed on 14 September 2012).

15. Zrodnikov, A.V.; Toshinsky, G.I.; Dragunov, Y.G.; Stepanov, V.S.; Komlev, O.G.; Klimov, N.N.; Kopytov, I.I.; Krushelnitsky, V.N. Nuclear power development in market conditions with use of multi-purpose modular fast reactors SVBR-75/100. Nuclear Eng. Des. 2006, 236, 1490-1502. 
16. Toshinsky, G.I.; Komlev, O.G.; Stepanov V.S.; Novikova, N.N.; Tormyshev, I.V.; Klimov, N.N.; Dedoul, A.V. Principles of Providing Inherent Self-Protection and Passive Safety Characteristics of the SVBR-75/100 Type Modular Reactor Installation for Nuclear Power Plants of Different Capacity and Purpose. In Proceedings of International Conference Advanced Nuclear Fuel Cycles and Systems (GLOBAL'07), Boise, ID, USA, 9-13 September 2007.

17. Novikova, N.N.; Komlev, O.G.; Toshinsky, G.I. Neutronic and Physical Characteristics of Reactor SVBR-75/100 with Different Types of Fuel. In Proceedings of ICAPP '06, Reno, NV, USA, 4-8 June 2006.

18. Zrodnikov, A.V.; Toshinsky, G.I.; Komlev, O.G.; Melnikov, K.G.; Novikova, N.N. Fuel cycle for reactor SVBR-100. J. Mater. Sci. Eng. B 1, 2011, 1, 929-937.

19. Chung, K.S.; Lee, J.S.; Song, K.S.; Song, K.C.; Yang, M.S. Research and Development Program of KAERI for DUPIC. In Proceedings of International Conference on Future Nuclear Systems: Emerging Fuel Cycles and Waste Disposal Options, GLOBAL'93, Seattle, WA, USA, 12-17 September 1993; American Nuclear Society: La Grange Park, IL, USA, 1993; Volume 2, p. 733.

(C) 2012 by the authors; licensee MDPI, Basel, Switzerland. This article is an open access article distributed under the terms and conditions of the Creative Commons Attribution license (http://creativecommons.org/licenses/by/3.0/). 